\title{
Ecstasy (3,4-Methylenedioxymethamphetamine): History, Neurochemistry, and Toxicology
}

\author{
Capt James $A$. Rochester, MD, USAF, MC, and Jeffrey T. Kirchner, DO
}

Background: 3,4-Methylenedioxymethamphetamine (MDMA; ecstasy), a compound chemically related to stimulant and hallucinogenic drugs, has been found to induce a state of euphoria and increased selfawareness. MDMA has been increasingly used for recreational purposes, especially among college students and other young adults, and has been associated with multiple toxic effects.

Methods: Using MEDLINE, the medical literature was searched from 1986 using the key words "ecstasy," "MDMA," and "designer drugs." Articles dating before 1986 were accessed from cross-reference of the more recent articles. A case report is described.

Results: MDMA was developed in 1912 as an appetite suppressant but never became commercially successful. It resurfaced in the 1950s as a psychotherapeutic agent. In 1985 MDMA was classified as a schedule 1 drug by the Food and Drug Administration after reports of neurotoxicity in laboratory animals. It again resurfaced in the mid 1980 s as a recreational drug used primarily among college students and other young adults. There are a number of case reports describing toxic effects from MDMA, including hyperthermia, rhabdomyolysis, coagulopathy, and acute renal failure. Little information is available regarding acute management or treatment of toxic ingestions.

Conclusions: MDMA ingestion has been associated with severe toxic effects. Although the literature describes numerous cases of toxic ingestion, there are no published recommendations or suggestions to guide physicians in the evaluation and treatment of such cases. By reviewing the history, neurochemistry, and toxicology of MDMA, as well as providing some guidance regarding management of toxic ingestion, we can arm the provider with valuable information for use in the acute setting. In addition, this information will assist providers in counseling young adults regarding the possible consequences of using this substance. (J Am Board Fam Pract 1999:12:137-42.)

3,4-Methylenedioxymethamphetamine (MDMA, ecstasy) is a compound chemically related to stimulant and hallucinogenic drugs that has been noted to induce a state of euphoria and increased self-awareness. It has been increasingly used for recreational purposes, especially among college students and other young adults. Its recreational use has been associated with multiple toxic effects. We present the results of a literature review and describe a case of toxic ingestion.

\section{Methods}

Using MEDLINE, the medical literature was searched from 1986 using the key works "ecstasy," "MDMA," and "designer drugs." Articles dating

Submitted, revised, 14 May 1998.

From the Department of Family and Community Medicine (JAR, JTK), Lancaster General Hospital, Lancaster, Pa. Address reprint requests to Jeffrey T. Kirchner, DO, Department of Family and Community Medicine, Lancaster General Hospital, Lancaster, PA 17604. before 1986 were accessed from cross-reference of the more recent articles.

\section{History of MDMA}

The first preparation and description of MDMA was through a patent issued by the E. Merck Pharmaceutical firm in Darmstadt, Germany, in 1912. The drug was developed as an appetite suppressant but never became commercially successful. It resurfaced in the 1950s as a method of lowering inhibitions in patients undergoing psychoanalysis. ${ }^{1}$ Patients using the drug found it gave them a sense of closeness with others around them. They believed it let down barriers or filters to free communication and aided in the introspective analysis of one's psyche. In 1983 a study performed on 29 volunteers (primarily academics and medical professionals), MDMA was found to be an adjunct to insight-oriented psychotherapy and to facilitate intimacy and communication between people involved in intimate relationships. ${ }^{2,3}$ 
Despite some of these reported benefits of MDMA, in July 1985 the Food and Drug Administration (FDA) placed the drug into the schedule 1 category, which greatly restricted its availability. ${ }^{1}$ Since that time its use as an adjunct to psychoanalytical therapy has greatly diminished, but its illicit use has become more common, perhaps in response to all of the attention given to MDMA by the lay press during the hearings that led to its schedule 1 classification.

Recreational use of MDMA began to surface in the early to mid 1980s. Reports from Ireland and college campuses in the United States showed its use was growing noticeably. Cases of ingestion reported by the Irish Poison Information Center increased 130 percent from January 1991 to June $1992 .{ }^{4}$ Recreational use by college students surveyed at a private southern university increased from 8 percent in 1986 to 24 percent in $1991 .{ }^{5}$ In addition, reports of adolescent knowledge of MDMA in England showed a dramatic increase in awareness of MDMA in the past 5 years. ${ }^{6}$

Currently most MDMA use occurs during "raves"-large (sometimes numbering thousands of participants) dance parties held in abandoned warehouses or other similar structures. Apart from techno-pop music and "smart drinks" (drinks laced with amino acid mixtures), MDMA seems to be an integral component of the rave scene.

\section{Case Report}

A 19-year-old man came to the emergency department by ambulance. The paramedics reported that they were called to a party where the patient had collapsed. Witnesses detailed that the young man had been at the party (a rave) for more than 30 hours and had taken several doses of ecstasy during this time. It was unknown whether he had consumed any other illicit substances or alcohol. No other medical history was available.

He was a well-developed, well-nourished man who was incoherent and agitated. His rectal temperature was $102.2^{\circ} \mathrm{F}\left(39^{\circ} \mathrm{C}\right)$; his blood pressure $140 / 96 \mathrm{mmHg}$, pulse 128 beats per minute, and respirations 24 per minute. Pulse oximetry was 100 percent on room air. Findings of his physical examination were also remarkable for flushed skin color as well as diaphoresis, slightly dilated pupils (4 to $5 \mathrm{~mm}$ in both eyes), a supple neck, and sinus tachycardia. Other than his fever, there were no signs of an infectious process. His neurologic ex $\stackrel{c}{3}$ amination showed him to be awake but disorim ented. His cranial nerves appeared intact, as dicis gross motor strength. Sensation to sharp prick ap $\rightarrow$ peared to be without deficit, deep tendon reflexeङ were brisk and symmetrical, and both toes were down-going on plantar stimulation.

Initial laboratory studies were remarkably nor mal except for a blood urea nitrogen of $68 \mathrm{mg} / \mathrm{dI}$ and creatinine of $1.3 \mathrm{mg} / \mathrm{dL}$; his white blood cele count was $11,000 / \mu \mathrm{L}$ with 44 percent neutrophils 12 percent band cells, and 28 percent lympho cytes. A urinalysis was normal except for an elevated specific gravity of 1.025 . The patient's ethanol level was $110 \mathrm{mg} / \mathrm{dL}$. A computed tomo $N$ graphic (CT) scan of the head showed no abnor $\frac{\widehat{0}}{0}$ malities. He had a normal opening pressure on $\mathrm{a}^{3}$ lumbar puncture, and no abnormalities were found with cerebrospinal fluid analysis. Initia urine toxicology screening was positive for amphetamines. Acetaminophen and salicylate levels were negative. Blood, urine, and cerebrospinak fluid were sent for culture.

The patient was admitted to the intensive care unit for close observation. He was rehydrated witho⿺ intravenous fluids and received three doses of dantrolene $(1 \mathrm{mg} / \mathrm{kg})$ intravenously to help control his hyperthermia. Empiric antibiotics were considered but withheld because infection was noto suspected. A toxicologic analysis of the urine showed MDMA. Seventy-two hours after admis 3 sion his dehydration and hyperthermia had re solved, and his complete blood cell count became normal. The cultures of blood, urine, and cere- $-\sum$ brospinal fluid were negative. He was subse quently discharged home with scheduled follow $-\overrightarrow{3}$ up in the substance abuse center of his localio university health center.

\section{Preparation of MDMA}

At least six methods of making MDMA are described in the scientific literature. Several recipes 0 can be located easily on the World Wide Web. Some specialized equipment is required as well as some expertise in organic chemical synthesis. Most expert black-market manufacturers recom- mend 1 to 2 years of undergraduate chemistry ex- -0 perience, including organic and analytic chemistry courses that have laboratory components. Prob- $\mathbb{D}$ lems with impure or incorrect synthesis can result ${ }^{\circ}$ in some rather potent and toxic contaminants, 
however, which could be the reason for toxic ingestions noted in the literature.

\section{Pharmacology}

In vivo and in vitro animal studies have shown that MDMA affects the serotonergic (and to a lesser extent dopaminergic) neurons of the brain. The compound seems to cause a calcium-independent flood of serotonergic neuron release into the synaptic cleft while inhibiting serotonin reuptake. This response results in the euphoria and stimulus effect of MDMA.

\section{Toxicology and Neurotoxicology}

Concerns about MDMA have arisen as a result of studies showing both reversible and possible irreversible damage to serotonergic neurons. ${ }^{7-15}$ These studies involved rats, rabbits, and nonhuman primates. Human studies of the effect of MDMA, which have been limited to indirect analysis through assays of cerebrospinal fluid obtained from patients, have shown conflicting results. Some studies have found a reduction in serotonin metabolites in the cerebrospinal fluid, suggesting a general depression or loss of serotonin from the brain. ${ }^{16}$ Another study showed no such loss of the serotonin metabolites. ${ }^{17}$ Because these studies were uncontrolled, the results are difficult to interpret. Ongoing controlled trials in Europe, as well as positron emission tomography (PET) scanning, could aid in further answering the question of neurotoxicity in humans. ${ }^{18}$

The lethal dose $\left(\mathrm{LD}_{50}\right)$ of MDMA has been studied in various animal models and by various routes of administration. Studies in rats have shown an $\mathrm{LD}_{50}$ of $49 \mathrm{mg} / \mathrm{kg}$ (parenterally) and $325 \mathrm{mg} / \mathrm{kg}$ orally. ${ }^{1}$ Nonhuman primate studies have shown an $\mathrm{LD}_{50}$ of $22 \mathrm{mg} / \mathrm{kg} .{ }^{13}$ While no $\mathrm{LD}_{50}$ studies in humans have been done, serum levels assayed on patients with toxic MDMA ingestions have approached or in some cases exceeded the primate $\mathrm{LD}_{50}$ dose.

\section{Case Reports of Adverse Reactions}

Most case reports in the medical literature have come from England, where the rave scene has been popular for quite some time. Since the early 1990 s, however, the phenomenon of raves has been transported to the United States, where they are gaining in popularity, especially in East Coast and West Coast cities. The most commonly seen
Table 1. Potential Complications of 3,4-Methylenedioxymethamphetamine (MDMA) Ingestion

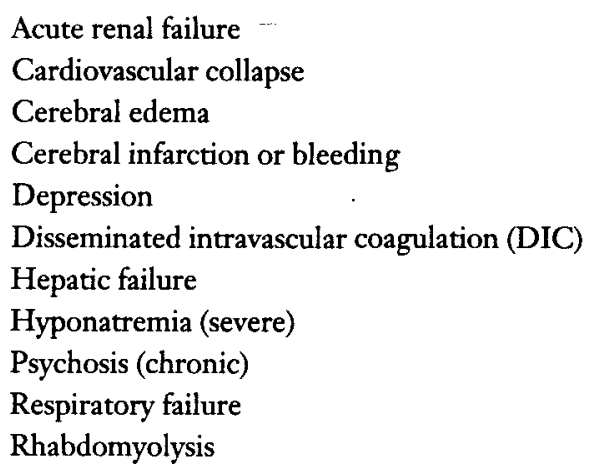

Adapted from references 19-42.

reaction to severe or toxic ingestion of MDMA is a syndrome of altered mental status, tachycardia, tachypnea, profuse sweating, and hyperthermia. This constellation of symptoms closely resembles that caused by acute amphetamine overdose, which is not surprising given the chemical similarity of MDMA. Severe reported complications from MDMA ingestion include rhabdomyolysis, acute renal failure, cardiac collapse, malignant hyperthermia, disseminated intravascular coagulation, hepatic failure, hyponatremia, urinary retention, cerebral infarct, and cerebral hemorrhage (Table 1). ${ }^{19-34}$ In addition, cases of profound psychosis and depression (once thought to be seen only in chronic users of MDMA) have been reported after minimal use. ${ }^{35-42}$

It is not yet known exactly what pathophysiologic role MDMA plays in the variety of adverse events that have been observed. Academic experts who advocate judicious use of the drug report no such reactions. Some believe that the conditions at a rave (a hot, crowded environment, poor ventilation, excessive physical exertion, dehydration), as well as toxic dosages of and contaminants in the preparations ingested, might be the culprits, not necessarily the MDMA itself. ${ }^{1,43,44}$ For these reasons MDMA continues for some to have a reputation as a safe recreational drug.

\section{Treatment}

Management of suspected MDMA overdose is the same as for any amphetamine overdose (Table 2). Attention to the ABCs (airway, breathing, circulation) should be the first priority. Assessment for ventricular dysrhythmias and hypertensive crisis should also be part of the initial assessment of these 
Table 2. Treatment of Toxic Ingestion of 3,4-Methylenedioxymethamphetamine (MDMA).

1. ABCs (airway, breathing, circulation)

2. Complete history and physical examination (emphasis on neurologic findings)

3. Cardiac monitoring and pulse oximetry

4. Oral charcoal and sorbitol, if ingestion occurred within 30 to $60 \mathrm{~min}$

5. Consider serum chemistries, liver function studies, complete blood cell count, urine toxicology screening, serum ethanol level, creatine kinase measurements, and arterial blood gas determinations

6. Monitor temperature and treat hyperthermia with a cooling blanket (dantrolene is controversial)

7. Insert Foley catheter to prevent urinary retention

8. Consider $\alpha$-blocker to treat hypertension

9. Consider $\boldsymbol{\beta}$-blocker to treat tachycardia

10. Intravenous fluids or dopamine to treat hypotension

11. Correct metabolic acidosis, if present

12. Intensive care unit monitoring with close observation of blood chemistries, hepatic transaminases, creatinine kinase, and urine output

patients. American Cardiac Life Support protocols should be initiated in the event of life-threatening dysrhythmias. Gastrointestinal decontamination using charcoal is also indicated. Initial studies should include a complete blood cell count, blood chemistry analysis, liver function tests, cardiac enzyme measurements (especially in the event of chest pain or dysrhythmias), creatine kinase measurements, and urine toxicology screening. Intravenous access is imperative. Other studies to consider are an electrocardiogram for chest pain, a chest radiograph for chest complaints, and a CT scan of the brain for persistent mental status change.

Treatment is then aimed at symptomatic management. Oxygen and intravenous fluids for hypotension; benzodiazepines or butyrophenones for agitation or seizures; dopamine or norepinephrine for hypotension unresponsive to fluid challenges; phentolamine or nitroprusside for hypertension; lidocaine for ventricular dysrhythmias; nitroglycerin for myocardial ischemic pain; aggressive cooling and possibly paralysis for hyperthermia (use of dantrolene is controversial ${ }^{45-47}$ ); fluids, mannitol, or bicarbonate for rhabdomyolysis; and correction of electrolyte abnormalities are all essential management principles in the care of these patients. Use of $\beta$-blockers is contraindicated because this might result in unopposed $\alpha$ adrenergic stimulation.
These patients should be admitted to the in tensive care unit for constant cardiac monitoring A Foley catheter should be inserted to monito\% urine output. Neurologic monitoring should be्g instituted along with frequent measurements of temperature, blood pressure, heart rate, and respi rations. Platelet count, blood chemistry determi? nations, liver function tests, and creatine kinas $\overrightarrow{\overline{\underline{\theta}}}$ measurements should be done regularly to asses? for the development of disseminated intravascula旁. coagulation, metabolic derangements, hepatotoxi $\bar{\Phi}_{2}$ city, and rhabdomyolysis. Once the patient be comes medically stable, particular attentio店 should be paid to evaluation of mood disorderw psychosis, and other psychiatric findings befor discharge.

\section{Recreational Use in Popular Culture} Information concerning the use and synthesis of MDMA is available through the Internet. Many sites on the World Wide Web discuss dosage methods for safe usage. These instructions are supported by literature from academics who have spent time studying the effects of and analyzing MDMA.1,2,43 Their recommended dosage is 20 $\mathrm{mg} / \mathrm{kg}$ as an initial dose with a booster dose after to 4 hours of 0.5 to $1 \mathrm{mg} / \mathrm{kg}$. It is also recoms mended that the user stay well-hydrated and re frain from vigorous physical activity to reduce the risk of serious hyperthermia and dehydration. An $\overrightarrow{\vec{\sigma}}$ other important safety tip is having a trip guide to protect the user from risky behavior. ${ }^{48}$ The cur rent street price of MDMA is $\$ 10$ to $\$ 30$ per dose The drug can be ingested orally, injected, smoked or snorted. The onset of action is directly related to the route of administration, and for an oral dose onset usually occurs in 30 to 45 minutes.

Psychologic effects of MDMA include enactogenesis (touching within) or a sensation that all is right with the world; empathogenesis, which is feeling of emotional closeness to others coupled. with a breakdown of personal communication barriers; and enhancement of the senses of touch taste, vision, smell, and proprioception. These $\mathrm{ef}_{\overline{0}}^{2}$ fects last approximately 4 to 6 hours, but a notice $-\frac{\mathbb{D}}{}$ able decrease in effect occurs within 2 to 3 hours.

Known side effects of MDMA include trismuso and bruxism for which gum chewing is recom $-\frac{\mathbb{D}}{\mathbb{D}}$ mended. The drug is contraindicated in persons taking monoamine oxidase inhibitors because it can cause malignant hyperthermic reactions. 
MDMA should also be avoided by persons who have a history of hypertension or cardiac, peripheral vascular, or renal disease because of its propensity to increase blood pressure.

\section{Final Comment}

Ecstasy, or MDMA, is a substance that has become popular with a subset of today's young adults. It has been associated with numerous fatal outcomes when used in improper situations or to excess. Because of the illicit nature of its production, impurities and toxic by-products are an additional hazard. The family physician should be aware that this drug, as well as many other socalled designer drugs, are being used in the community. The clinician should also be prepared to deal with the consequences of MDMA ingestion in patients who have a constellation of symptoms described in the patient above. Further research is needed (and currently underway) to define better the pharmacologic effects of MDMA and determine whether it might be of therapeutic benefit to the medical and psychiatric communities.

\section{References}

1. Shulgin AT. The background and chemistry of MDMA. J Psychoactive Drugs 1986;18:291-304.

2. Greer G, Tolbert R. Subjective reports of the effects of MDMA in a clinical setting. J Psychoactive Drugs 1986;18;319-27.

3. Lister MB, Grob CS, Bravo GL, Walsh RN. Phenomenology and sequelae of 3,4-methylenedioxymethamphetamine use. J Nerv Ment Dis 1992;180: 345-52.

4. Cregg MT, Tracey JA. Ecstasy abuse in Ireland. Ir Med J 1993;86:118-20.

5. Cuomo MJ, Dyment PG, Gammino VM. Increasing use of "Ecstasy" (MDMA) and other hallucinogens on a college campus. J Am Coll Health 1994: 42:271-4.

6. Wright JD, Pearl L. Knowledge and experience of young people regarding drug misuse, 1969-94. BMJ 1995;310:20-4.

7. Battaglia G, Yeh SY, O'Hearn E, Molliver ME, Kuhr HJ, DeSouza EB. 3,4-Methylenedioxymethamphetamine and 3,4-methylenedioxyamphetamine destroy serotonin terminals in rat brain: quantification of neurodegeneration by measurement of $[3 \mathrm{H}]$ paroxetine-labeled serotonin uptake sites. J Pharmacol Exp Ther 1987;242:911-6.

8. Brodkin J, Malyala A, Nash JF. Effect of acute monoamine depletion on 3,4-methylenedioxymethamphetamine-induced neurotoxicity. Pharmacol Biochem Behav 1993;45:647-53.
9. Commins DL, Vosmer G, Virus RM, Woolverton WL, Schuster CR, Seiden LS. Biochemical and histological evidence that methylenedioxymethamphetamine (MDMA) is toxic to neurons in the rat brain. J Pharmacol Exp Ther 1987;241:338-45.

10. McKenna DJ, Peroutka SJ. Neurochemistry and neurotoxicity of 3,4-methylenedioxymethamphetamine (MDMA, "ecstasy"): J Neurochem 1990;54:14-22.

11. Molliver ME, Berger UV, Mamounas LA, Molliver DC, O'Hearn E, Wilson MA. Neurotoxicity of MDMA and related compounds: anatomic studies. Ann NY Acad Sci 1990;600:649-64.

12. O'Hearn E, Battaglia G, DeSouza EB, Kuhr MJ, Molliver ME. Methylenedioxyamphetamin (MDA) and methylenedioxymethamphetamine (MDMA) cause selective ablation of serotonergic axon terminals in forebrain: immunocytochemical evidence for neurotoxicity. J Neurosci 1988;8:2788-803.

13. Ricaurte GA, McCann UD. Neurotoxic amphetamine analogues: effects in monkeys and implications for humans. Ann NY Acad Sci 1992;648:371-82.

14. Ricaurte GA, Martello AL, Katz JL, Martello MB. Lasting effects of (+ -)-3,4-methylenedioxymethamphetamine (MDMA) on central serotonergic neurons in nonhuman primates: neurochemical observations. J Pharmacol Exp Ther 1992;261:616-22.

15. Stone DM, Stahl DC, Hanson GR, Gibb JW. The effects of 3,4-methylenedioxymethamphetamine (MDMA) and 3,4-methylenedioxyamphetamine (MDA) on monoaminergic systems in the rat brain. Eur J Pharmacol 1986;128:41-8.

16. Ricaurte GA, Finnegan KT, Irwin I, Langston JW. Aminergic metabolites in cerebrospinal fluid of humans previously exposed to MDMA: preliminary observations. Ann NY Acad Sci 1990;600:699-710.

17. Peroutka SJ, Pascoe N, Faull KF. Monoamine metabolites in the cerebrospinal fluid of recreational users of 3,4-methylenedioxymethamphetamine (MDMA; "ecstasy"). Res Commun Substance Abuse 1987;8:125-38.

18. Steele TD, McCann UD, Ricaurte GA. 3,4-Methylenedioxymethamphetamine (MDMA, "Ecstasy"): pharmacology and toxicology in animals and humans. Addiction 1994;89:539-51.

19. Barrett PJ, Taylor GT. "Ecstasy" ingestion: a case report of severe complications. J R Soc Med 1993; 86:233-4.

20. Brown C, Osterloh J. Multiple complications from recreational ingestion of MDMA ("Ecstasy"). JAMA 1987;258:780-1.

21. Bryden AA, Rothwell PJ, O'Reilly PH. Urinary retention with misuse of "ecstasy." BMJ 1995;310:504.

22. Chadwick IS, Curry PD, Linsley A, Freemont AJ, Doran B. Ecstasy, 3,4-methylenedioxymethamphetamine (MDMA), a fatality associated with coagulopathy and hyperthermia. J R Soc Med 1991; $84: 371$. 
23. Dowling GP, McDonough ET 3d, Bost RO. "Eve" and "Ecstasy." A report of five deaths associated with the use of MDEA and MDMA. JAMA 1987;252: 1615-7.

24. Henry JA, Jeffreys KJ, Dawling S. Toxicity and deaths from 3,4-methylenedioxymethamphetamine ("ecstasy"). Lancet 1992;340:384-7.

25. Hughes JC, McCabe $M$, Evans RJ. Intracranial haemorrhage associated with ingestion of "ecstasy." Arch Emerg Med 1993;10:372-4.

26. Kessel B. Hyponatraemia after ingestion of ecstasy. BMJ 1994;308:414.

27. Manchanda S, Connolly MJ. Cerebral infarction in association with Ecstasy abuse. Postgrad Med J 1993;69:874-5.

28. Marsh JC, Abboudi ZH, Gibson FM, Scopes J, Daly S, O'Shaunnessy DF, et al. Aplastic anemia following exposure to 3,4-methylenedioxymethamphetamine ("ecstasy"). Br J Haematol 1994;88:281-5.

29. Maxwell DL, Polkey MI, Henry JA. Hyponatremia and catatonic stupor after taking "ecstasy." BMJ 1993;307:1399.

30. Nimmo SM, Kennedy BW, Tullett WM, Blyth AS, Dougall JR. Drug-induced hyperthermia. Anaesthesia 1993;48:892-5.

31. Oranje WA, von Pol P, vd Wurff A, Zeijen RN, Stockbrugger RW, Arends JW. XTC-induced hepatitis. Neth J Med 1994;44:56-9.

32. Satchell SC, Connaughton $M$. Inappropriate antidiuretic hormone secretion and extreme rises in serum creatinine kinase following MDMA ingestion. $\mathrm{Br} J$ Hosp Med 1994;51:495.

33. Screaton GR, Singer M, Cairns HS, Thrasher A, Sarner M, Cohen SL. Hyperpyrexia and rhabdomyolysis after MDMA ("ecstasy") abuse. Lancet 1992; 339:677-8.

34. Suarez RV, Riemersma R. "Ecstasy" and sudden cardiac death. Am J Forensic Med Pathol 1988;9:339-41.
35. Creighton FJ, Black DL, Hyde CE. "Ecstasy" psychosis and flashbacks. Br J Psychiatry 1991;159: 713-5.

36. McCann UD, Ricaurte GA. MDMA ("ecstasy") and panic disorder: induction by a single dose. Biol Psychiatry 1992;32:950-3.

37. McCann UD, Ricaurte GA. Lasting neuropsychi- ֶ๊ atric sequelae of $( \pm$ ) methylenedioxymethampheta $-\stackrel{+}{\rightarrow}$ mine ("ecstasy") in recreational users. J Clin Psychopharmacol 1991;11:302-5.

38. McGuire P, Fahy T. Chronic paranoid psychosis af $-\frac{\bar{c}}{\bar{c}}$ ter misuse of MDMA ("ecstasy"). BMJ 1991;302:त्ष్ 697.

39. Pallanti S, Mazzi D. MDMA (Ecstasy) precipitation of panic disorder. Biol Psychiatry 1992;32:91-5.

40. Schifano $\mathrm{F}$. Chronic atypical psychosis associated with MDMA ("ecstasy") abuse. Lancet 1991;338:1335.

41. Whitaker-Azmitia PM, Aronson TA. "Ecstasy" (MDMA)-induced panic. Am J Psychiatry 1989;146: 119.

42. Williams H, Meagher D, Galligan P. M.D.M.A. $\cdot \vec{\omega}$ ("Ecstasy"); a case of possible drug-induced psychosis. Ir J Med Sci 1993;162:43-4.

43. Greer F, Strassman RJ. Information on "Ecstasy." Am J Psychiatry 1985;142(11):1391.

44. Newmeyer JA. $X$ at the crossroads. J Psychoactive Drugs 1993;25(4):341-2.

45. Barrett PJ. Ecstasy and dantrolene. BMJ 1992; 305 1225.

46. Padkin A. Treating MDMA ("ecstasy") toxicity. Anaesthesia 1994:49:259.

47. Webb C, Williams V. Ecstasy intoxication: apprecia- $\stackrel{\mathbb{D}}{\stackrel{D}{2}}$ tion of complications and the role of dantrolene. $\overrightarrow{0}$ Anaesthesia 1993;48:542-3.

48. Taylor JM. MDMA: Frequently asked questions.

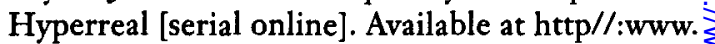
hyperreal.org. Accessed 1997. 